\title{
Medico-Legal Age Estimation in Living Individual from a Portuguese Population: Third Molar Mineralization
}

\author{
Mário Silva Branco ${ }^{1}$, Dinis Pestana ${ }^{2,3}$, Cristiana Palmela Pereira ${ }^{3,4,5 *}$
}

${ }^{1}$ Private Dental Practitioner, Project master thesis author, Portugal

${ }^{2}$ Professor, Department of Statistics and Operation Research. Faculty of Sciences, University of Lisbon, Portugal

Investigator from Center of Statistics and Applications of University of Lisbon (CEAUL), Portugal

${ }^{4}$ Professor, Dental School from University of Lisbon \& Forensic Odontologist, South Branch from Portuguese National Institute of Legal Medicine, Portugal ${ }^{5}$ Investigator from CENCIFOR, Center of Forensic Studies, Portugal

\begin{abstract}
According to the Study Group on Forensic Age Diagnostics (AGFAD), the radiological evaluation of third molar mineralization is a major criterion for chronological age estimation of living individuals.

This investigation studied third molar development in 329 orthopantomograms (40.4\% males) of Portuguese individuals, patients of Dental Medicine Faculty of Lisbon University, with an age range between 14,0 to 22,8 years, through five different methods (Demirjian, Haavikko, Harris and Nortjè, Kullman and Solari).

The results show a better correlation, between real and estimated age, in Demirjian and Solari methods. Demirjian method was used to analyse the other results statistical variables. Third molar development occurs earlier, in average 9 months, in males, in stages D-G. In stage $\mathrm{H}$ there's no significant difference. There's no significant difference between mineralization of molars in the same arch, however, in the inter-arch comparison, the maxillary molars have a premature development, statistically different in stages $\mathrm{F}$ (males), $\mathrm{G}$ and $\mathrm{H}$.

The age 18 is reach in stage $\mathrm{G}$ and $\mathrm{H}$, respectively, by females and males. Under the Portuguese Penal Code, section 19 , the age is one of the factors of exceptional of criminal responsibility. For criminal pursuit, they state being minor than 16 years of age. This limit is reached for both sexes in the stadium F. However in any stage we can deduce the majority or minority in relation to the age of criminal responsibility.
\end{abstract}

New studies about the influence of socioeconomic and genetic factors, in third molar development, are necessary

Keywords: Forensic identification; Dental age estimation; Orthopantomogram; Dental development; Third molar

\section{Introduction}

In Forensic Sciences, chronological age estimation, in medico-legal cases, has been increasingly important [1], being one of the application fields of Forensic Dentistry [2]. Traditionally used in cadavers and human remains identification, the importance in living individuals has been expanding in the last years [2-4], especially because the increase of immigration phenomenon [5]. The applicability is in criminal law (document validation, imputability and political asylum) and civil law (social benefits, job and marriage) $[5,6]$.

In a way to obtain consensus between scientists and clarify the protocol to apply, when estimating age, it was founded in March 2000, in Berlin (Germany), the international and interdisciplinary Study Group on Forensic Age Diagnostics (AGFAD) [4], defining that age estimation, in living individuals, should consist in [2-4,7]:

$>$ Physical examination - anthropometrical measures (such as height and weight); signs of sexual maturation; identification of age-relevant development disorders.

$>\mathrm{X}$-ray examination of the left hand.

$>$ Dental examination - dentition status and orthopantomogram.

> X-ray or CT examination of the medial clavicular epiphysis (exam indicated when the hand development is complete).

The methods should be used together to improve the precision [4], but recorded separately and the age estimation declared has the more probable, specifying the degree of probability associated to each result
[3]. While in the childhood and preadolescence, the age estimation, based on morphologic methods by radiological evaluation of dental and bone development, is accurate, with increasing age, the precision is, progressively, smaller [6]. Between 14 and 22 years old, medico-legal age estimation is very important but also very problematic to estimate with higher accuracy $[4,5,8]$. In Portuguese Legislation, imputability, by age, is over 16 years old, according to $19^{\text {th }}$ article of Portuguese Penal Code. Based on the Portuguese jurisdiction of criminal law, this is the age range with major legal implications and with higher number of forensic cases to do age estimation in living persons.

In this age range, the only indicator, by dental methods, is the mineralization and eruption of third molar [5,8], but this methodology has been questioned [8]. Mainly because of population intra and intervariability $[5,9,10$,$] . However, several recent studies consider it an$ appropriated marker $[5,8,9,11]$. The mineralization of third molar is determined, primarily, by genetic factors [5] and less influenced, than eruption, by environmental factors, like malnutrition, illness and stress

${ }^{*}$ Corresponding author: Professor, Cristiana Palmela Pereira, Department of Biomaterials, School of Dentistry, University of Lisbon, Lisbon, Portugal, E-mail: cristiana.pereira@fmd.ul.pt

Received March 07, 2012; Accepted April 12, 2012; Published April 14, 2012

Citation: Branco MS, Pestana D, Pereira CP (2012) Medico-Legal Age Estimation in Living Individual from a Portuguese Population: Third Molar Mineralization. J Forensic Res 3:149. doi:10.4172/2157-7145.1000149

Copyright: (c) 2012 Branco MS, et al. This is an open-access article distributed under the terms of the Creative Commons Attribution License, which permits unrestricted use, distribution, and reproduction in any medium, provided the original author and source are credited. 
[8]. The variability could be related to sex, age, rate of dental maturation [10] and ethnic origin [2].

There are several methods to classify dental mineralization by stages, although the validity of forensic age estimation in the courts depends, mainly, in the accuracy of the method used [10]. Dental development has a intra and inter-population variability, so there's a need to study distinct population affinities $[8,12]$. In Portugal, medicolegal age estimation, from dental classification systems, is based on methods published for others populations, so it's necessary to do it also based on a Portuguese population, because of the internationality of criminal law. The main goal of this investigation was to estimate the age, in a Portuguese population, under medico-legal investigation, through estimate of chronological age, applying several methods performed in other populations.

The main goal results in the formulation of several secondary objectives:

$>$ Evaluate the influence of sex in third molar mineralization.

$>$ Evaluate the symmetry between dental development by the third molar in right and left side and between upper and lower jaw.

$>$ Evaluate the accuracy of the dental development stages of the third molar in the Portuguese population according to their application in criminal law.

$>$ Validation of standard dental methods of medico-legal age estimation through the third molar mineralization for the Portuguese population.

Dvaluate the quality assurance of medico-legal age estimation in the Portuguese medico-legal system.

\section{Materials and Methods}

In this study were analyzed 329 orthopantomograms of 133 males and 196 females Portuguese individuals with known age, sex and full name, all of whom were from Portugal including their father and mother. The X-rays were selected from the clinical files of the patients from the Dental Faculty of University from Lisbon, between 2006 and 2010. The present investigation was approved and realized with the consent of Ethics for Health Committee (Process 3/2006) of the faculty.

Additional criteria of inclusion were: absence of dental pathology; existence of at least two third molars, and where one was mandibular; absence of deformities in the area of interest, which affected the analyses. The information such as file number, sex, date of birth and date of the orthopantomogram were registered. A document was created associating the file number to a specific number of the project, in order to enable observer's access to data and ensure data confidentiality. The document was destroyed in the end of the study according to Ethic Committee.

The chronological age, in each case, was calculated from the birth and orthopantomogram date. The age range was 14,0 to 22,8 years old. The maturation stage of third molar (maxillary and mandibular) was obtained by the analysis of orthopantomograms. The classification methods of dental mineralization used were: Demirjian Method [13], Haavikko Method [14], Harris and Nortjè Method [15], Kullman Method [16] and Solari Method - modification of Demirjian Method [9].

The orthopantomograms were analyzed by the same observer that gave, to each of the third molars, presents on the $\mathrm{x}$-ray, a rate, corresponding to the development stage, following the description criteria and/or comparing the $\mathrm{x}$-rays to representative schemes of each stage. In case of significant differences in development stages, between roots of the same teeth, the lowest value was endorsed, except in Harris and Nortjè Method, because evaluated rot was the mesial one, due to the method's specification. The procedure was repeated for each method. When third molar wasn't present and/or had an atypical anatomy, wasn't included on the study. In Harris and Nortjè and Kullman Methods was attributed the rate "NA" (Not applied), when the molar presented crown development, because those methods only consign root development stages.

The kappa coefficient $(k)$ was used to calculate the intra-observer agreement. Was performed one month after initial analysis on a random sample of $20 \%$ of all radiographs analyzed. According to central limit theorem and knowing that the sample was $\mathrm{N} \geq 30$, then it was assumed that the sample approximated to a normal uniform distribution, being analysed by parametric tests.

The Pearson correlation coefficient was used to determine the dental method with a better interdependency between chronological and estimated age and between contra lateral third molars to determine the left-right symmetry for Portuguese population. The p-value was calculated to determine the significance of the sample. Significance was established to $p<0,05$ and determined to evaluate the occurrence of sexual dimorphism and statistically differences in development stages between maxillary and mandibular third molars.

The statistical analysis was realized using date analysis options of Microsoft Office Excel 2007 to Windows Vista.

\section{Results}

From the 329 orthopantomograms analyzed, $40.4 \%(\mathrm{~N}=133)$ correspond to males and $59.6 \%(\mathrm{~N}=196)$ to females. The age distribution by sex is very similar for both sexes (Table 1 ).

There were no statistically significant intra-observer differences between the two times of measurements. The $k$ coefficient determine was 0.89 .

The Pearson correlation coefficient was used to determine the correlation between chronological and estimated age, based on the stages for each method analyzed to determine statistically which method had the best correlation for Portuguese population (Tables 2 and 3). The Demirjian and Solari methods for both sex were the methods with best results for Portuguese population. The highest score was obtained with the Demirjian methods (0.828) apply to the

\begin{tabular}{|l|c|c|}
\hline Age & Males $(\mathrm{N}=133)$ & Females $(\mathrm{N}=196)$ \\
\hline Mean age & 18,9 & 19,3 \\
\hline Minimum age & 14,0 & 14,2 \\
\hline Maximum age & 22,8 & 22,7 \\
\hline Standard deviation & 2,29 & 1,95 \\
\hline
\end{tabular}

Table 1: Age distribution by sex.

\begin{tabular}{|c|c|c|c|c|}
\hline Method & 18 & 28 & 38 & 48 \\
\hline Harris and Nortjè & & & 0,751 & 0,753 \\
\hline Kullman & & & 0,794 & 0,789 \\
\hline Haavikko & 0,740 & 0,749 & 0,801 & 0,797 \\
\hline Solari & $\mathbf{0 , 7 8 0}$ & 0,788 & 0,823 & $\mathbf{0 , 8 2 3}$ \\
\hline Demirjian & 0,767 & $\mathbf{0 , 7 9 0}$ & $\mathbf{0 , 8 2 8}$ & 0,821 \\
\hline
\end{tabular}

Table 2: Pearson correlation coefficient - Males. 
tooth 38 in males. The Kullman method also gave very good results for this population. The results with the Harris and Nortjè and Haavikko methods were the worsted when applied to Portuguese population. The third mandibular molars (38 and 48) showed statistically better results than the maxillary ones. The correlation obtained in males was highest than in females, being this difference statistically significant ( $p$ $=0.005$ ). Based on the previous results such as the method with the best correlation we will empathize the Demirjian method in this paper to analyze the further data.

Table 4 list the mean age and standard deviation for each third molar development stages, by sex and teeth. None of the analyzed teeth had A and B stages. The C stage had a reduced sample $(\mathrm{N}=1)$, so wasn't include in the statistical analysis.

Regarding the data we concluded there was statistically significant differences between sexual discrimination and stages: $\mathrm{D}(p=0.009)$, $\mathrm{E}(p=0.007), \mathrm{F}(p<0.001)$ and $\mathrm{G}(p<0.001)$. Therefore, males have a earlier third molar maturation (average 9 months) than females. In $\mathrm{H}$ stage, the differences between sexes was statistically irrelevant ( $p=$ 0.233 ). These results were similar for both jaws.

Comparing maxillary and mandibular molars, there was a tendency to an earlier mineralization of the firsts that is statistically significant in stages: $\mathrm{F}$ (males: $p=0.023$ ), $\mathrm{G}$ (males: $p=0.011$; females: $p=0.003$ ) and $\mathrm{H}$ (males: $p=0.041$; females: $p=0.016$ ).

Tables 5 and 6 are a cross tabulation, with the goal to establishing the synchrony of dental development, between teeth of the same jaw (left-right symmetry). Pearson correlation coefficient, in males, was 0.96 (maxillary teeth) and 0.97 (mandibular teeth). In females, despite lower (0.94 to both jaws), revealed also a very importance evidence.

Tables 7 and 8 corroborate the previously conclusions, since males presents development stages in a premature phase. Individuals in

\begin{tabular}{|l|c|c|c|c|}
\hline Method & 18 & 28 & 38 & 48 \\
\hline Harris and Nortjè & & & 0,638 & 0,697 \\
\hline Kullman & & & 0,754 & 0,790 \\
\hline Haavikko & 0,735 & 0,745 & 0,756 & 0,787 \\
\hline Solari & 0,743 & 0,752 & 0,769 & $\mathbf{0 , 7 9 0}$ \\
\hline Demirjian & $\mathbf{0 , 7 4 6}$ & $\mathbf{0 , 7 6 0}$ & $\mathbf{0 , 7 7 3}$ & 0,784 \\
\hline
\end{tabular}

Table 3: Pearson correlation coefficient - Females.

\begin{tabular}{|c|c|c|c|c|c|c|}
\hline \multicolumn{2}{|c|}{ Stage } & D & E & $\mathrm{F}$ & G & $\mathrm{H}$ \\
\hline \multirow{4}{*}{$\begin{array}{l}\frac{\infty}{c} \\
\frac{f}{0} \\
\stackrel{0}{\circ}\end{array}$} & \multirow{2}{*}{$\mathrm{F}$} & $15,5(11)$ & $16,3(13)$ & $17,6(12)$ & $18,5(14)$ & $20,0(136)$ \\
\hline & & 0,98 & 1,15 & 1,58 & 1,09 & 1,33 \\
\hline & \multirow{2}{*}{$\mathrm{M}$} & $15,1(9)$ & $15,4(8)$ & $16,0(7)$ & $17,6(6)$ & $19,9(91)$ \\
\hline & & 0,87 & 1,37 & 1,07 & 0,92 & 1,55 \\
\hline \multirow{4}{*}{$\begin{array}{l}\stackrel{\infty}{N} \\
\text { ᄃ } \\
\stackrel{0}{0} \\
\stackrel{\circ}{\circ}\end{array}$} & \multirow{2}{*}{$\mathrm{F}$} & $15,3(6)$ & 16,3 (18) & $17,5(13)$ & 18,9 (28) & $20,2(123)$ \\
\hline & & 0,69 & 1,37 & 1,27 & 1,28 & 1,28 \\
\hline & \multirow{2}{*}{$M$} & $15,1(8)$ & $15,8(12)$ & $16,0(7)$ & $17,5(10)$ & 20,1 (88) \\
\hline & & 0,93 & 1,44 & 1,31 & 0,78 & 1,44 \\
\hline \multirow{4}{*}{ 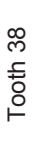 } & \multirow{2}{*}{$\mathrm{F}$} & $15,6(16)$ & $16,9(13)$ & $18,1(25)$ & $19,5(52)$ & $20,4(78)$ \\
\hline & & 1,07 & 1,67 & 1,27 & 1,22 & 1,21 \\
\hline & \multirow{2}{*}{ M } & $14,9(9)$ & $15,6(10)$ & $17,0(17)$ & $18,8(17)$ & $20,3(79)$ \\
\hline & & 0,86 & 1,31 & 1,33 & 1,52 & 1,25 \\
\hline \multirow{4}{*}{ 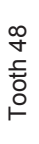 } & \multirow{2}{*}{$\mathrm{F}$} & $15,6(9)$ & $16,2(17)$ & $18,1(28)$ & $19,4(53)$ & $20,5(80)$ \\
\hline & & 1,11 & 1,56 & 1,20 & 1,34 & 1,06 \\
\hline & \multirow{2}{*}{$M$} & $14,7(6)$ & $15,7(10)$ & $16,8(16)$ & $18,5(18)$ & $20,3(76)$ \\
\hline & & 0,4 & 1,42 & 1,21 & 1,61 & 1,25 \\
\hline
\end{tabular}

Table 4: Mean age and standard deviation, in each stage of third mola development, based on Demirjian method; $(\mathrm{N})$ - number of teeth in each sample; F - Females; M - Males. stage $\mathrm{D}$ has a zero probability of being at least 18 years old, meanwhile individuals in stage $\mathrm{G}$ and $\mathrm{H}$ has high probability of being at least 16 years old. The stage $\mathrm{H}$ also presents high probability of an individual, in that stage, has a chronological age of at least 18 years old. However, in all this stages were observed individuals with less than 16 and 18 years old.

Another approach of data analyses would be the combined use of the 5 methods. Then, for each individual, depending of the development stage, in the different methods, would be calculated the $95 \%$ confidence bounds for each stage, based in the available data base. The final result, for each tooth, would result in the intersection of the 3 or 5 confidence bounds, depending if it's a upper or lower molar, respectively. For example, selecting a female, randomly, with the following mineralization stages (table 9). Checking the tables were defined the confidence bounds, for each tooth, choosing the maximum value of the inferior limit and the minimum value of superior limit. Therefore, the confidence bounds, for each tooth, are: 18 (16,125-21.285), 28 (17,264-23,052), 38 (17,186-22,327), 48 (16,309-21.000). The final result, for this specific individual, would result in the intersection of the confidence bounds associated to each tooth, then the estimated age would be between 17,264-21,000 years old.

\section{Discussion}

The guidelines of AGFAD about medico-legal age estimation in living individuals, comprehend a physical and dental examination, $\mathrm{x}$-ray of the left hand and/or clavicle and orthopantomogram [4]. The combined use of these methods, assure an increased precision [17], more important it is in criminal law in the living individuals than in cadaver [18]. This evidence is supported by Garamendi et al. [3], that realized a general physical examination by Tanner's method, left hand $\mathrm{x}$-ray with application of the Greulich and Pyle method and a general dental examination complemented with orthopantomogram, using the Demirjian method. This study analyzed 114 Moroccan individuals with age range between 13-25 years old and determined that the combination of dental and skeletal methods, improve, significantly, the chronological age prediction, recommending, consequently, the guidelines of AGFAD.

The utilization of x-ray or CT of the clavicle [19] is consigned to the cases where the wrist ossification is complete [20]. The complete ossification of medial clavicular epiphysis is, primarily, observed in ages of 21 years [21] or 22 years [22]. This result has a forensic importance, because the complete ossification allows classifying the majority of an individual, relatively, to the ages of legal relevance [20]. However, the results most be analyzed with precaution. The inter-group variability and the results from the group studied may be different in another group with a different status socio-economical and with a different impact on ossification [21]. The only study that contradicts is from Galstaun, from 1937, and he referred the complete ossification at the age of 19, however, there's no differentiation between partial and complete ossification, what, probably, influenced the results [cit in. 22].

A better precision is accomplished when we have more teeth under development $[9,23]$. However, during late adolescence, only the third molar isn't completed mineralized [5,23]. This is the reason why it is being proposed by the lack of another reliable biological marker for forensic age estimation $[9,24]$. Furthermore the wrist ossification, that showed good results [3,20], can be used, approximately, until 16 years old [25] and extend until 19 years old [cit in. 20]. This feature, additionally, with the apex closure of the second molar completed, 


\begin{tabular}{|c|c|c|c|c|c|c|}
\hline & \multicolumn{5}{|c|}{ Tooth 28 } \\
\hline Tooth 18 & D & E & F & G & H & Total \\
\hline D & $\mathbf{8}$ & 1 & & & & 9 \\
\hline E & & $\mathbf{7}$ & 1 & & & 8 \\
\hline F & & 2 & $\mathbf{4}$ & 1 & & 7 \\
\hline G & & & 1 & $\mathbf{4}$ & 1 & 6 \\
\hline H & & & 1 & 5 & $\mathbf{8 4}$ & 90 \\
\hline Total & 8 & 10 & 7 & 10 & 85 & 121 \\
\hline
\end{tabular}

\begin{tabular}{|c|c|c|c|c|c|c|}
\hline & \multicolumn{5}{|c|}{ Tooth 48 } \\
\hline Tooth 38 & D & E & F & G & H & Total \\
\hline D & $\mathbf{6}$ & 3 & & & & 9 \\
\hline E & & $\mathbf{6}$ & 3 & & & 9 \\
\hline F & & 1 & $\mathbf{1 3}$ & 1 & & 15 \\
\hline G & & & & $\mathbf{1 5}$ & 2 & 17 \\
\hline H & & & & 2 & $\mathbf{7 4}$ & 76 \\
\hline Total & 6 & 10 & 16 & 18 & 76 & 127 \\
\hline
\end{tabular}

Table 5: Cross tabulation of development stages, by Demirjian method, between maxillary and mandibular teeth, respectively, in males.

\begin{tabular}{|c|c|c|c|c|c|c|}
\hline & \multicolumn{5}{|c|}{ Tooth 28} \\
\hline Tooth 18 & D & E & F & G & H & Total \\
\hline D & $\mathbf{6}$ & 4 & & & & 10 \\
\hline E & & $\mathbf{1 2}$ & 1 & & & 13 \\
\hline F & & 2 & $\mathbf{9}$ & 1 & & 12 \\
\hline G & & & 2 & 11 & 1 & 14 \\
\hline H & & & 1 & 16 & $\mathbf{1 1 6}$ & 133 \\
\hline Total & 6 & 18 & 13 & 28 & 117 & 182 \\
\hline
\end{tabular}

\begin{tabular}{|c|c|c|c|c|c|c|}
\hline & \multicolumn{6}{|c|}{ Tooth 48 } \\
\hline Tooth 38 & D & E & F & G & H & Total \\
\hline D & $\mathbf{9}$ & 6 & 1 & & & 16 \\
\hline E & & $\mathbf{1 0}$ & 3 & & & 13 \\
\hline F & & 1 & $\mathbf{2 1}$ & 2 & 1 & 25 \\
\hline G & & & 1 & $\mathbf{4 1}$ & 7 & 49 \\
\hline H & & & & 7 & $\mathbf{6 5}$ & 72 \\
\hline Total & 9 & 17 & 26 & 50 & 73 & 175 \\
\hline
\end{tabular}

Table 6: Cross tabulation of development stages, by Demirjian method, between maxillary and mandibular teeth, respectively, in females.

approximately, at the age of 14 [25], delineate this age, as the minimum age of inclusion in this study. The maximum age is 22 years, according to Solari \& Abramovitch recommendations [9].

The orthopantomogram by its convenience, quickness and information quality is the technique of choice, to assess third molar mineralization [9], which is compounded by the fact that is used in all studies accessed by the authors, as well as been proposed by AGFAD guidelines. The major disadvantage, during the use of the technique, was the superposition of anatomical structures, that difficult mainly the analysis of maxillary third molar $[10,26]$.

The inclusion criteria of to include only the orthopantomograms that had a minimum of one inferior third molar, was due to the specificity of Harris and Nortjè and Kullman methods [15,16], which are only consign to lower molars, allowing us the application of the 5 methods to all of the orthopantomograms of this study. To the absent molars wasn't endorse a specific nomenclature, because the research of agenesis prevalence wasn't defined as a study goal, unlike other studies [10]. The attribution of the lowest value, when differences between roots of the same tooth occurred, meted the protocols established in previous studies [5,27], in a way to standardize the procedure. The definition of the population of Portuguese origin by the family name, followed the same guidelines $[5,9,24,28,29,30]$. The methodology in Harris and Nortjè method, apply that the evaluation was done using the third molar mesial root [15].

According to AGFAD recommendations should be defined the socio-economical status and health to outwit the existence of exogenous factors that may influence the psychosomatic development. However, like it was proved by others studies, dental mineralization is an independent variable without influence of those factors, on the contrary, of skeletal development and their anthropometric measurements $[3,5,23,24,31]$. So, in the present study, no data about external factors were collected. The orthopantomogram was dropout of the study when revealed obvious signs of dental pathology.

Nowadays, one of the most important question, is concerning to the influence of population affinity in individual development. There are different studies that compare different populations and concluded that there is a difference between the dental mineralization timing between different populations [8,24,30,31,32,33]. Comparing our results from our population with previous ones (Table 10), Portuguese are similar to Canadian and American populations, having the Spanish population a faster development $[2,8,9,13,34$. The Hispanics had an earlier development in the stages F and G, comparing to Portuguese population. Regarding German, Japanese and South-African populations, they have a slower development than the Portuguese population $[2,8,9,13,34]$. However, these results most be analysed with scientific criteria, since Olze et al. [2] had a age range between 12-26 years old, wider than the one of this study and the other ones compared to $[3,5,8-10,13,24,27,28,32,33,34]$ (Table 11). This observation may explain our results of highest values in mean age, with more relevance, in latter development stages, specially, in stage $\mathrm{H}$. Therefore, the use of an inferior maximum age limit most decreases the mean age values presented [9]. Consequently, more studies are needed to compare different populations, with higher sample size and under the same methodological criteria, in order to identify the influence of social and genetic factors in dental development [24].

Demirjian method is consider to be the simplest and the more objective method with the highest results in the correlation between estimated and real age and in the inter-observer correlation [31]. His major advantage is the methodology that is based on shape and/ or proportion changes, without metric estimation [8]. Originally, wasn't described to the third molar, nowadays it is recommended by the American Board of Forensic Odontologists (ABFO) and applied in many studies [24]. The adaptation to the third molar was proposed by Mincer et al. [13]. An alteration by Kasper et al. [27], added representative $\mathrm{x}$-ray images to each stage to simplify the evaluation process. One of the disadvantages is the reduced number of stages in the development of the last half of the root [18], so was added two intermediate stages $\left(F_{1}\right.$ and $\left.G_{1}\right)$, with the goal to increase the accuracy in the assessment [9].

The Demirjian and Kullman methods were the two methods chosen in our study due to the good correlation between the two variables: chronological and estimated age [31]. The other ones chosen, Harris and Nortjè and Haavikko methods, despite the weak evidence of the first one, are methods that betake to the estimation of root length, with or without specification to the mandibular molars, so were introduce to compare the less or higher correlation between estimate and real age, with methods based on size and/or proportion changes. The use of Solari method was due to the possible improves of his modification. 


\begin{tabular}{|c|c|c|c|c|c|c|}
\hline \multicolumn{2}{|c|}{ Stages } & D & E & F & G & H \\
\hline \multirow{2}{*}{ Tooth 18 } & F & $100 \%(11)$ & $92 \%(12)$ & $\mathbf{5 8 \% ~ ( 7 ) ~}$ & $14 \%(2)$ & $5 \%(7)$ \\
\cline { 2 - 7 } & M & $100 \%(9)$ & $100 \%(8)$ & $\mathbf{1 0 0 \% ( 7 )}$ & $67 \%(4)$ & $12 \%(11)$ \\
\hline \multirow{2}{*}{ Tooth 28 } & F & $100 \%(6)$ & $89 \%(16)$ & $\mathbf{5 4 \% ( 7 )}$ & $18 \%(5)$ & $3 \%(4)$ \\
\cline { 2 - 7 } & M & $100 \%(8)$ & $92 \%(11)$ & $\mathbf{1 0 0 \% ( 7 )}$ & $60 \%(6)$ & $10 \%(8)$ \\
\hline \multirow{2}{*}{ Tooth 38 } & F & $100 \%(16)$ & $62 \%(8)$ & $\mathbf{4 4 \% ( 1 1 )}$ & $6 \%(3)$ & $3 \%(2)$ \\
\cline { 2 - 7 } & M & $100 \%(9)$ & $90 \%(9)$ & $\mathbf{8 2} \%(\mathbf{1 4})$ & $35 \%(6)$ & $5 \%(4)$ \\
\hline \multirow{2}{*}{ Tooth 48 } & F & $100 \%(9)$ & $82 \%(14)$ & $\mathbf{3 9 \% ( 1 1 )}$ & $11 \%(6)$ & $0 \%(0)$ \\
\cline { 2 - 7 } & M & $100 \%(6)$ & $90 \%(9)$ & $\mathbf{8 8 \% ( 1 4 )}$ & $44 \%(8)$ & $4 \%(3)$ \\
\hline
\end{tabular}

Table 7: Probability of an individual be less than 18 years old, based on development stages (Demirjian method).

\begin{tabular}{|c|c|c|c|c|c|c|}
\hline \multicolumn{2}{|c|}{ Stages } & $\mathrm{D}$ & $\mathrm{E}$ & $\mathrm{F}$ & $\mathrm{G}$ & $\mathrm{H}$ \\
\hline \multirow{2}{*}{ Tooth 18 } & $\mathrm{F}$ & $27 \%(3)$ & $69 \%(9)$ & $83 \%(10)$ & $100 \%(14)$ & $99 \%(135)$ \\
\cline { 2 - 7 } & $\mathrm{M}$ & $11 \%(1)$ & $25 \%(2)$ & $43 \%(3)$ & $100 \%(6)$ & $99 \%(90)$ \\
\hline \multirow{2}{*}{ Tooth 28} & $\mathrm{~F}$ & $17 \%(1)$ & $61 \%(11)$ & $85 \%(11)$ & $100 \%(28)$ & $99 \%(122)$ \\
\cline { 2 - 7 } & $\mathrm{M}$ & $13 \%(1)$ & $25 \%(3)$ & $57 \%(4)$ & $100 \%(10)$ & $99 \%(87)$ \\
\hline \multirow{2}{*}{ Tooth 38 } & $\mathrm{F}$ & $31 \%(5)$ & $69 \%(9)$ & $100 \%(25)$ & $100 \%(52)$ & $99 \%(77)$ \\
\cline { 2 - 7 } & $\mathrm{M}$ & $11 \%(1)$ & $30 \%(3)$ & $71 \%(12)$ & $100 \%(17)$ & $100 \%(79)$ \\
\hline \multirow{2}{*}{ Tooth 48 } & $\mathrm{F}$ & $33 \%(3)$ & $47 \%(8)$ & $100 \%(28)$ & $98 \%(52)$ & $100 \%(80)$ \\
\cline { 2 - 7 } & $\mathrm{M}$ & $0 \%$ & $30 \%(3)$ & $69 \%(11)$ & $94 \%(17)$ & $100 \%(76)$ \\
\hline
\end{tabular}

Table 8: Probability of an individual be at least 16 years old, based on development stages (Demirjian method).

\begin{tabular}{|l|c|c|c|c|}
\hline Method & 18 & 28 & 38 & 48 \\
\hline Harris and Nortjè & & & 5 & 5 \\
\hline Kullman & & & $\mathrm{A}_{\mathrm{c} 1}$ & $\mathrm{R}_{\mathrm{c}}$ \\
\hline Haavikko & $\mathrm{R}_{\mathrm{c}}$ & $\mathrm{A}_{\mathrm{c}}$ & $\mathrm{R}_{\mathrm{c}}$ & $\mathrm{R}_{3 / 4}$ \\
\hline Solari & $\mathrm{G}_{1}$ & $\mathrm{H}$ & $\mathrm{G}_{1}$ & $\mathrm{G}$ \\
\hline Demirjian & $\mathrm{G}$ & $\mathrm{H}$ & $\mathrm{G}$ & $\mathrm{G}$ \\
\hline
\end{tabular}

Table 9: Development stages for each tooth and stage of the individual.

This study (Table 2 and 3) found that the methods with better correlation, between estimated and real age, are Demirjian and Solari methods. Results showed that there's a strong correlation to both methods [31]. The option of assess the remaining data based in Demirjian method was due to the small number of cases in $F_{1}$ and $G_{1}$ stages, what also doesn't allow to deduced the increased precision of Solari method [9].

The development of third molar presents sexual dimorphism (Table 4), occurring earlier in males in the Portuguese population. This difference is statistically significant ( 9 months in average) to the results between stages $D-G$, in both jaws, similar to the results presented in other studies $[5,9,12]$, where the variation is between 6-9 months [8] to one year [32]. The difference, in stage $\mathrm{H}$, hasn't statistical significant [24], probably, due to a tendency to equalize in maturity [8]. The fact that development occurs earlier in males is characteristic of third molars, whereas in the other permanent teeth, dental development is faster in females [5]. Of all the consulted literature, only, Bolaños et al. [10], show similar development between both sexes. This divergence, to our study, may be due to: (1) the difference between age range (4-20 years old in Bolaños); (2) the major goal for his study was to determine the agenesis prevalence. Olze et al. [31] limited his study to females, however, the mainly aim was to verify the most effective method of age estimation, in forensic field, and the age range was wider that in other study (12-25 years old). Garamendi et al. [3] just analysed males. Nowadays, this author, points as a restriction the fact that the results can't be extrapolated to females.

The same table, table 4 , allows us to assess the earliest development in upper teeth, comparing to the lower ones. The fact is statistically significant in $\mathrm{F}$ (males), $\mathrm{G}$ and $\mathrm{H}$ stages. However, in all other stages there are a tendency to a later mineralization of lower molars. This result is transversal to all studies consulted (Table 11). The fact that the upper molars mineralize earlier, may disown them to secondary importance [32], once the mineralization of lower teeth allows the assessment of real age for a longer period, more so, the statistic evidence is more significant in advanced stages. In addition, we could add the fact that the observation of the upper teeth is difficult by the overlap of anatomical structures [10].

The analysis of table 4 also let us to verify that the individuals distribution isn't as homogeneous as the authors wanted, since a high percentage of cases is encompassed in the final stages of dental maturation, particularly, in stage $\mathrm{H}$, being more pronounced in males. This could be explain by the high average age (Table 1). Then is recommended that in a next study in Portuguese population, the number of individuals in earlier ages will need to be higher, in order to standardize the sample size. The table 5 and 6 allow us to analyse the left-right symmetry. In the present study, the correlation is very strong and there aren't differences between arches, unlike the results obtain with the studies from Gunst et al. [5], Solari \& Abramovitch [9] and Mincer et al. [13] in which all of them the agreement is greater in maxilla than in mandible (Table 11). This observation could be explained by the difficulty in assess the maxillary third molar that remits probably the observer to the development stages similar to both maxillary teeth. Besides that, the results of this study suggest as very strong to strong the correlation between teeth in the same arch. Regarding sex, symmetry is higher in males. When the values analyzed are extended to a stage below or above the concordance value, the correlation rate is between 0.99-1.00, like in Kasper et al. [27]. The only study in which the symmetry is absent (Table 11) is from Mincer et al. [13], that had a medium concordance of 0.78 . In spite of the high evidence in left-right symmetry, in medico-legal age estimation, all teeth should be assessed, independently [27]. The same should be applied to studies in medicolegal chronological age estimation, to avoid unnecessary errors.

One of the major goals of this study was to evaluate the dental development in the ages of Portuguese criminal law: 16 and 18 years old. In the tables 7 and 8 are represented the probability of an individual in the different stages of dental development be respectively less than 18 years old or at least 16 years old. The probability of an individual be less or at least 18 years old is high, respectively, in $\mathrm{D}$ and $\mathrm{H}$ stages, while the $\mathrm{G}$ and $\mathrm{H}$ stages present high probability of an individual be over 16 years old. However, isn't possible to have statistical differences. Therefore, the error associated to the methodology, doesn't allow us to consider it great in medico-legal age estimation $[3,24]$. This could let to methodology unacceptable errors or ethically unacceptable errors. In the first case fall the individuals that, being at least 16 or 18 years old (according to the criminal law) are considerer minors, taking to a more benevolent conduct and extra charges, due to the necessity of special protection measures, relegate only to minors. In the second case fall the individuals that being under the age set down by the law are considerer over 16 or 18 years old, leading to a violation of humans minors rights [3]. Therefore, we conclude that as an isolated criteria the third molar development isn't valid [32], however, the association to other methods raise, considerably, the accuracy [3], so the analysis of the methods, with the knowledge of their limitations and the agreement and discrepancy between each other, should be done, to establish with the highest efficiency that it is possible, the chronological age of the individual [8] and decrease the number of false positives - ethically unacceptable errors - and false negatives - technically unacceptable errors [3]. 
Citation: Branco MS, Pestana D, Pereira CP (2012) Medico-Legal Age Estimation in Living Individual from a Portuguese Population: Third Molar Mineralization. J Forensic Res 3:149. doi:10.4172/2157-7145.1000149

Page 6 of 8

\begin{tabular}{|c|c|c|c|c|c|c|c|c|}
\hline \multirow{2}{*}{ Stage/Gender } & \multicolumn{2}{|c|}{ E } & \multicolumn{2}{|c|}{$\mathrm{F}$} & \multicolumn{2}{|c|}{ G } & \multicolumn{2}{|c|}{$\mathrm{H}$} \\
\hline & Female & Male & Female & Male & Female & Male & Female & Male \\
\hline \multirow{2}{*}{$\begin{array}{l}\text { French-Canadian } \\
\text { (Demirjian et al. [34]) }\end{array}$} & 15,40 & 15,40 & 17,30 & 16,95 & 19,50 & 18,40 & 20,70 & 19,20 \\
\hline & $-1,05^{a}$ & $-0,25^{\mathrm{a}}$ & $-0,60^{\mathrm{a}}$ & $0,29^{\mathrm{a}}$ & $0,21^{\mathrm{a}}$ & $0,06^{\mathrm{a}}$ & $0,46^{a}$ & $-0,93^{a}$ \\
\hline \multirow{2}{*}{$\begin{array}{l}\text { American } \\
\text { (Mincer et al. [13]) }\end{array}$} & $16,9(1,7)$ & $17,3(2,5)$ & $17,7(1,8)$ & $17,5(2,1)$ & $19,1(1,9)$ & $18,3(1,9)$ & $20,9(2,0)$ & $20,5(1,9)$ \\
\hline & $0,45^{a}$ & $1,65^{a}$ & $-0,20^{a}$ & $0,84^{a}$ & $-0,19^{\mathrm{a}}$ & $-0,04^{a}$ & $0,66^{a}$ & $0,37^{a}$ \\
\hline \multirow{2}{*}{$\begin{array}{l}\text { Hispanic Americans } \\
\text { (Solari \& Abramovitch [9]) }\end{array}$} & $16,1(1,4)$ & $15,8(1,2)$ & $17,3(2,6)$ & $16,3(1,3)$ & $18,5(2,1)$ & $17,1(1,7)$ & $21,7(1,8)$ & $20,6(2,3)$ \\
\hline & $-0,35^{a}$ & $0,15^{a}$ & $-0,60^{a}$ & $-0,36^{a}$ & $-0,79^{a}$ & $-1,24^{a}$ & $1,46^{a}$ & $0,47^{\mathrm{a}}$ \\
\hline \multirow{2}{*}{$\begin{array}{l}\text { German } \\
\text { (Olze et al.[2]) }\end{array}$} & $17,2(2,4)$ & $16,7(2,1)$ & $19,0(2,5)$ & $18,2(2,1)$ & $21,6(2,1)$ & $21,2(1,9)$ & $22,9(1,7)$ & $22,5(1,7)$ \\
\hline & $0,75^{\mathrm{a}}$ & $1,05^{a}$ & $1,10^{\mathrm{a}}$ & $1,54^{\mathrm{a}}$ & $2,31^{a}$ & $2,86^{a}$ & $2,66^{a}$ & $2,37^{a}$ \\
\hline \multirow{2}{*}{$\begin{array}{l}\text { Japonese } \\
\text { (Olze et al. [2]) }\end{array}$} & $18,2(2,3)$ & $18,6(2,9)$ & $20,3(1,9)$ & $19,8(2,2)$ & $21,5(1,8)$ & $21,8(2,1)$ & $22,1(1,8)$ & $22,5(1,8)$ \\
\hline & $1,75^{a}$ & $2,95^{a}$ & $2,4^{a}$ & $3,14^{a}$ & $2,21^{a}$ & $3,46^{a}$ & $1,86^{a}$ & $2,37^{a}$ \\
\hline \multirow{2}{*}{$\begin{array}{l}\text { South African } \\
\text { (Olze et al. [2]) }\end{array}$} & $15,9(2,3)$ & $15,2(2,4)$ & $17,4(2,5)$ & $18,7(2,3)$ & $19,8(2,3)$ & $20,8(2,2)$ & $22,4(1,9)$ & $22,6(1,9)$ \\
\hline & $-0,55^{a}$ & $-0,45^{a}$ & $-0,50^{a}$ & $2,48^{a}$ & $0,51^{a}$ & $2,46^{a}$ & $2,16^{a}$ & $2,47^{a}$ \\
\hline \multirow{2}{*}{$\begin{array}{l}\text { Spanish } \\
\text { (Prieto et al. [8]) }\end{array}$} & $15,99(1,42)$ & $15,22(1,03)$ & $16,83(1,56)$ & $16,43(1,34)$ & $18,41(1,43)$ & $17,92(1,50)$ & $19,66(0,97)$ & $19,74(1,08)$ \\
\hline & $-0,46^{a}$ & $-0,43^{a}$ & $-1,07^{a}$ & $-0,23^{\mathrm{a}}$ & $-0,88^{a}$ & $-0,42^{\mathrm{a}}$ & $-0,58^{a}$ & $-0,39^{a}$ \\
\hline $\begin{array}{l}\text { Portuguese } \\
\text { (Our study, 2010) }\end{array}$ & $16,45(1,43)$ & $15,65(1,35)$ & $17,90(1,30)$ & $16,66(1,25)$ & $19,29(1,28)$ & $18,34(1,43)$ & $20,24(1,24)$ & $20,13(1,36)$ \\
\hline
\end{tabular}

Table 10: Mean age (standard deviation), in years, in different populations, based on Demirjian method (adapted from Prieto et al, 2005). a - Difference (in years) comparing to our study with Portuguese population.

\begin{tabular}{|c|c|c|c|c|c|c|c|c|}
\hline Study & Population & $A D$ & $\mathbf{N}$ & SD & IA-S & Method & EA-S & Notes \\
\hline Solari A \& Abramovitch K [9] & Hispanics & $14-25$ & 679 & $\begin{array}{c}\text { Present } \\
(\widehat{(})\end{array}$ & Present & Solari & Absent (Maxilla) & \\
\hline Prieto JL et al. [8] & Spanish & $14-21$ & 1054 & $\begin{array}{c}\text { Present } \\
(\lesssim)\end{array}$ & Present & Demirjian & -- & Study in IM \\
\hline Garamendi PM et al. [3] & Moroccan & $13-25$ & 114 & --- & Present & Demirjian & --- & Study in IM of $\hat{\delta}$ \\
\hline Martin-de las Heras et al. [24] & $\begin{array}{l}\text { Spanish } \\
\text { Magrebian }\end{array}$ & $14-23$ & $\begin{array}{c}477 \\
95\end{array}$ & $\begin{array}{c}\text { Present } \\
(\gtrsim)\end{array}$ & Present & Demirjian & Absent (Maxilla) & \\
\hline Gunst K et al. [5] & Belgian & $15-23$ & 2513 & $\begin{array}{c}\text { Present } \\
\left({ }^{\lambda}\right)\end{array}$ & Present & Köhler & Absent (Maxilla) & \\
\hline Bolaños MV et al. [10] & Spanish & $4-20$ & 786 & Absent & Present & Nolla & Absent (Maxilla) & \\
\hline Knell B et al. [32] & Swiss ${ }^{£}$ & $15-22$ & 1260 & $\begin{array}{c}\text { Present } \\
\left(0^{\lambda}\right)\end{array}$ & Present & Demirjian & --- & Study in IM \\
\hline Zeng DL et al. [33] & Chinese & $4-26$ & 3100 & $\begin{array}{c}\text { Present } \\
(\lesssim)\end{array}$ & Present & Demirjian & Absent (Maxilla) & \\
\hline Kasper KA et al. [27] & $\begin{array}{l}\text { Hispanics } \\
\text { (Texas) }\end{array}$ & $12-22$ & 950 & $\begin{array}{c}\text { Present } \\
\left(\delta^{\lambda}\right)\end{array}$ & Present & Demirjian & Absent (Maxilla) & \\
\hline Salvia AD et al. [28] & Spanish & $14-25$ & 400 & $\begin{array}{c}\text { Present } \\
(\delta)\end{array}$ & --- & $\begin{array}{c}\text { Demirjian } \\
\text { Solari }\end{array}$ & -- & Study in one IM \\
\hline Mincer $\mathrm{HH}$ et al. [13] & American & $14-24$ & 823 & $\begin{array}{c}\text { Present } \\
\left(\partial^{\lambda}\right)\end{array}$ & Absent & Demirjian & Absent (Maxilla) & \\
\hline Demirjian A et al. [34] & French & $2-20$ & 2928 & Present $(+)$ & Present & Demirjian & -- & Evaluation from $\mathrm{Cl}$ to $2^{\circ} \mathrm{M}$ \\
\hline
\end{tabular}

Table 11: Resume board of the results obtained in different studies consulted. AD - Age distribution (in years); N - Number of individuals; SD - Sexual dimorphism (gender with early development); IA-S - Intra-arch synchrony; EA-S - Inter-arch synchrony (arch with early development); IM - Inferior molar; CI - Central incisor; Notes: $£$ - 9,76\% of the sample were from other European countries (unspecified).

\begin{tabular}{|c|c|c|c|c|c|c|}
\hline \multirow[b]{2}{*}{ Tooth } & \multirow[b]{2}{*}{ Gender } & \multicolumn{5}{|c|}{ Harris and Nortjè Method } \\
\hline & & 1 & 2 & 3 & 4 & 5 \\
\hline \multirow{2}{*}{38} & $\mathrm{~F}$ & $11,712-20,667$ & $14,407-20,777$ & $14,310-21,265$ & $14,885-21,475$ & $17,186-22,988$ \\
\hline & M & $13,229-16,900$ & * & $13,322-20,458$ & $14,692-18,768$ & $17,336-22,767$ \\
\hline \multirow{2}{*}{48} & $\mathrm{~F}$ & $12,932-18,314$ & $12,080-23,224$ & $15,112-20,528$ & $14,519-21,889$ & $16,204-23,149$ \\
\hline & $\mathrm{M}$ & $12,850-17,455$ & * & $12,948-20,619$ & $15,557-19,061$ & $16,666-23,305$ \\
\hline
\end{tabular}

Table 12: $95 \%$ Confidence bounds to Harris and Nortjè Method. F - Female; $M$ - Male; * $-\mathrm{N}$ (sample size) insufficient.

\begin{tabular}{|c|c|c|c|c|c|c|c|c|}
\hline & & \multicolumn{5}{|c|}{ Kullman Method } \\
\hline \multirow{2}{*}{ Tooth } & Gender & $\mathrm{R}_{\mathrm{i}}$ & $\mathrm{R}_{1 / 4}$ & $\mathrm{R}_{1 / 2}$ & $\mathrm{R}_{3 / 4}$ & $\mathrm{R}_{\mathrm{c}}$ & $\mathrm{A}_{\mathrm{c} 1}$ \\
\hline \multirow{2}{*}{38} & $\mathrm{~F}$ & $12,428-18,541$ & $*$ & $13,528-21,178$ & $14,875-21,108$ & $14,401-22,617$ & $16,680-22,425$ & $17,643-23,164$ \\
\cline { 2 - 8 } & $\mathrm{M}$ & $12,730-17,495$ & $13,414-16,609$ & $13,465-19,606$ & $13,395-20,862$ & $13,169-22,238$ & $15,403-21,977$ & $17,774-22,762$ \\
\hline \multirow{2}{*}{48} & $\mathrm{~F}$ & $12,878-17,847$ & $12,014-20,210$ & $13,546-21,810$ & $14,944-21,141$ & $15,243-21,402$ & $16,379-22,569$ & $18,093-22,959$ \\
\cline { 2 - 9 } & $\mathrm{M}$ & $13,366-16,161$ & $12,159-18,393$ & $11,835-21,631$ & $13,215-20,619$ & $13,995-23,302$ & $13,962-22,344$ & $17,412-23,129$ \\
\hline
\end{tabular}

Table 13: 95\% Confidence bounds to Kullman Method. F - Female; M - Male; * - N (sample size) insufficient. 


\begin{tabular}{|c|c|c|c|c|c|c|c|}
\hline \multirow[b]{2}{*}{ Tooth } & \multirow[b]{2}{*}{ Gender } & \multicolumn{6}{|c|}{ Haavikko Method } \\
\hline & & $\mathrm{R}_{\mathrm{i}}$ & $\mathrm{R}_{1 / 4}$ & $\mathrm{R}_{1 / 2}$ & $\mathrm{R}_{3 / 4}$ & $\mathrm{R}_{\mathrm{c}}$ & $A_{c}$ \\
\hline \multirow{2}{*}{18} & $\mathrm{~F}$ & $12,491-19,113$ & * & $13,723-19,278$ & $13,398-22,326$ & $15,708-21,440$ & $17,022-23,040$ \\
\hline & M & $11,0,75-20,393$ & $14,231-15,053$ & $12,981-17,840$ & $12,861-21,184$ & $15,137-19,923$ & $16,837-22,992$ \\
\hline \multirow{2}{*}{28} & $\mathrm{~F}$ & $12,624-18,598$ & * & $13,148-20,058$ & $13,904-21,176$ & $15,854-21,932$ & $17,264-23,052$ \\
\hline & M & * & $13,942-15,785$ & $13,067-18,347$ & $13,050-19,614$ & $15,640-19,453$ & $17,198-22,925$ \\
\hline \multirow{2}{*}{38} & $\mathrm{~F}$ & $12,591-18,274$ & * & $13,738-21,666$ & $14,565-21,366$ & $16,365-22,412$ & $17,643-23,164$ \\
\hline & M & $13,566-15,769$ & $13,712-16,642$ & $12,995-19,711$ & $13,821-20,548$ & $15,272-21,840$ & $17,774-22,762$ \\
\hline \multirow{2}{*}{48} & $\mathrm{~F}$ & $12,912-18,053$ & $11,571-20,479$ & $14,389-21,081$ & $15,106-21,188$ & $16,152-22,532$ & $18,093-22,959$ \\
\hline & M & $11,482-18,607$ & $13,014-17,070$ & $12,554-21,150$ & $13,219-20,560$ & $14,435-22,327$ & $17,412-23,129$ \\
\hline
\end{tabular}

Table 14: 95\% Confidence bounds to Haavikko Method. F - Female; M - Male; * $-\mathrm{N}$ (sample size) insufficient.

\begin{tabular}{|c|c|c|c|c|c|c|c|c|}
\hline \multirow[b]{2}{*}{ Tooth } & \multirow[b]{2}{*}{ Gender } & \multicolumn{7}{|c|}{ Solari Method } \\
\hline & & $D$ & $E$ & $\mathrm{~F}$ & $\mathrm{~F}_{1}$ & G & $\mathrm{G}_{1}$ & $\mathrm{H}$ \\
\hline \multirow{2}{*}{18} & $\mathrm{~F}$ & $12,954-18,097$ & $13,383-19,249$ & $13,472-21,659$ & * & $12,264-23,727$ & $16,125-21,332$ & $17,022-23,040$ \\
\hline & $M$ & $13,117-17,131$ & $12,124-18,615$ & $13,224-18,379$ & * & $14,367-21,077$ & * & $16,837-22,992$ \\
\hline \multirow{2}{*}{28} & $\mathrm{~F}$ & $13,086-17,456$ & $12,895-19,630$ & $13,896-20,899$ & * & $14,530-23,222$ & $16,061-21,743$ & $17,264-23,052$ \\
\hline & $M$ & $12,910-17,301$ & $12,599-18,918$ & $13,327-18,899$ & * & * & $15,577-19,254$ & $17,198-22,925$ \\
\hline \multirow{2}{*}{38} & $\mathrm{~F}$ & $12,952-18,286$ & $12,659-21,211$ & $14,881-21,277$ & $14,166-21,807$ & $15,533-22,848$ & $16,981-22,327$ & $17,643-23,164$ \\
\hline & M & $12,956-16,925$ & $12,619-18,525$ & $13,885-20,550$ & $14,129-18,993$ & $15,284-22,430$ & $15,103-22,458$ & $17,774-22,762$ \\
\hline \multirow{2}{*}{48} & $\mathrm{~F}$ & $13,102-19,198$ & $12,378-20,097$ & $14,756-21,215$ & $15,570-21,000$ & $15,236-21,937$ & $16,811-22,572$ & $18,093-22,959$ \\
\hline & $M$ & $13,289-16,033$ & $11,649-19,668$ & $13,296-20,102$ & $14,575-19,792$ & $12,368-24,302$ & $14,882-22,241$ & $17,412-23,129$ \\
\hline
\end{tabular}

Table 15: $95 \%$ Confidence bounds to Solari Method. F - Female; M - Male; * - N (sample size) insufficient.

\begin{tabular}{|c|c|c|c|c|c|c|}
\hline \multirow[b]{2}{*}{ Tooth } & \multirow[b]{2}{*}{ Gender } & \multicolumn{5}{|c|}{ Demirjian Method } \\
\hline & & $\mathrm{D}$ & $E$ & $\mathrm{~F}$ & G & $\mathrm{H}$ \\
\hline \multirow{2}{*}{18} & $\mathrm{~F}$ & $12,954-18,097$ & $13,383-19,249$ & $13,472-21,659$ & $15,782-21,285$ & $17,022-23,040$ \\
\hline & $M$ & $13,117-17,131$ & $12,124-18,615$ & $13,384-18,644$ & $15,202-19,952$ & $16,837-22,992$ \\
\hline \multirow{2}{*}{28} & $\mathrm{~F}$ & $13,086-17,456$ & $12,895-19,630$ & $13,896-20,899$ & $15,854-21,932$ & $17,264-23,052$ \\
\hline & $M$ & $12,901-17,301$ & $12,599-18,918$ & $12,812-19,238$ & $15,783-19,309$ & $17,198-22,925$ \\
\hline \multirow{2}{*}{38} & $\mathrm{~F}$ & $12,952-18,286$ & $12,659-21,211$ & $15,015-21,091$ & $16,711-22,366$ & $17,643-23,164$ \\
\hline & M & $12,956-16,925$ & $12,619-18,525$ & $14,156-19,816$ & $15,587-22,028$ & $17,774-22,762$ \\
\hline \multirow{2}{*}{48} & $\mathrm{~F}$ & $13,102-19,198$ & $12,378-20,097$ & $15,235-20,949$ & $16,309-22,490$ & $18,093-22,959$ \\
\hline & $M$ & $13,289-16,033$ & $11,649-19,668$ & $13,766-19,814$ & $14,520-22-427$ & $17,412-23,129$ \\
\hline
\end{tabular}

Table 16: $95 \%$ Confidence bounds to Demirjian Method. F - Female; M - Male; * - N (sample size) insufficient.

The statistic analysis based on the 5 methods of dental mineralization wasn't described by any study consulted until this was realized according to our proposal at the Ethics Committee. The approach was to determine for each method, tooth and stage, the $95 \%$ confidence bound, in other words, instead of a single value, is given an interval of probable estimations (Tables 12, 13, 14, 15 and 16). The confidence bounds were, in general, wider, however, they could decrease, with a higher sample size in future studies with Portuguese population. Their use in chronological age estimation, in medicolegal field, could be relevant, since the introduction of new data, in each case analysed, could take to a decrease in the confidence bounds and, therefore, raise the efficiency of the estimation. Yet, this fact presupposes the existence of a data base for comparison. The legitimacy of this analysis will need to be revise in a more exhaustive study, since isn't excepted independency of the results, because the mineralization stages presents some degree of dependency, since they are similar in the features examine.

\section{Conclusions}

The chronological age estimation is nowadays of great importance in Forensic Sciences, mainly in the criminal law field. The establishment of international guidelines and quality assurance in living individuals through the methodology with a general physic examination, left hand X-ray and clinical dental observation complete with orthopantomogram, give more reliable results to criminal law application. In late adolescence, the medico-legal age estimation is done scientific by dental criteria, particularly by the evaluation of the third molar mineralization, since all teeth had completed their formation. In spite of their variability in terms of size, agenesis, time of mineralization and eruption, the third molar is at present a good criteria.

The results from this study suggest the third molar as good criteria to chronological age estimation for Portuguese population. However, its use should be always associated to the remaining parameters however it is possible like is recommend it, to increase the accuracy and the validation of age estimation. The third molar, unlike the remaining permanent teeth, mineralize earlier in Portuguese males, principally, in D to $\mathrm{G}$ stages. In stage $\mathrm{H}$ this difference isn't statistically significant for Portuguese population. For this population exist leftright symmetry statistically significant, i.e., the tooth $18 / 28$ and $38 / 48$ have a mineralization stage extremely concordant. The upper third molars mineralize earlier that the lower ones. In Portuguese criminal law, the ages 16 and 18 years old are the mainly ages for the medicolegal examination according to the court. The present study concluded that in any development stage it is possible to estimate the majority or minority of a Portuguese individual, based exclusively in third molar mineralization. 
Citation: Branco MS, Pestana D, Pereira CP (2012) Medico-Legal Age Estimation in Living Individual from a Portuguese Population: Third Molar Mineralization. J Forensic Res 3:149. doi:10.4172/2157-7145.1000149

\section{Acknowledgment}

Research partially sponsored by national funds through the Fundação Nacional para a Ciência e Tecnologia, Portugal - FCT under the project (PEst-OE/ MAT/UI0006/2011).

\section{References}

1. Foti B, Lalys L, Adalian P, Giustiniani J, Maczel M, et al. (2003) New forensic approach to age determination in children based on tooth eruption. Forensic Sci Int 132: 49-56.

2. Olze A, Schmeling A, Taniguchi M, Maeda H, van Niekerk $P$, et al. (2004) Forensic age estimation in living subjects: the ethnic factor in wisdom tooth mineralization. Int J Legal Med. 118: 170-173.

3. Garamendi PM, Landa MI, Ballesteros J, Solano MA (2005) Reliability of the methods applied to assess age minority in living subjects around 18 years old. A survey on a Moroccan origin population. Forensic Sci Int 154: 3-12.

4. Schmeling A, Geserick G, Reisinger W, Olze A (2007) Age estimation. Forensic Sci Int 165: 178-181.

5. Gunst K, Mesotten K, Carbonez A, Willems G (2003) Third molar root development in relation to chronological age: a large sample sized retrospective study. Forensic Sci Int 136: 52-57.

6. Ritz-Timme S, Cattaneo C, Collins MJ, Waite ER, Schütz HW (2000) Age estimation: The state of the art in relation to the specific demands of forensic practise. Int J Legal Med 113: 129-136.

7. Schmeling A, Olze A, Reisinger W, Geserick G (2004) Forensic age diagnostics of living people undergoing criminal proceedings. Forensic Sci Int 144: 243245.

8. Prieto JL, Barbería E, Ortega R, Magaña C (2005) Evaluation of chronological age based on third molar development in the Spanish population. Int $\mathrm{J}$ Legal Med 119: 349-354.

9. Solari AC, Abramovitch K (2002) The accuracy and precision of third molar development as an indicator of chronological age in Hispanics. J Forensic Sci 47: $531-535$

10. Bolaños MV, Moussa H, Manrique MC, Bolaños MJ (2003) Radiographic evaluation of third molar development in Spanish children and young people. Forensic Sci Int 133: 212-219.

11. Orhan K, Ozer L, Orhan AI, Dogan S, Paksoy CS (2007) Radiographic evaluation of third molar development in relation to chronological age among Turkish children and youth. Forensic Sci Int 165: 46-51.

12. Lewis JM, Senn DR (2010) Dental age estimation utilizing third molar development: A review of principles, methods, and population studies used in the United States. Forensic Sci Int 79-83.

13. Mincer HH, Harris EF, Berryman HE (1993) The A.B.F.O. study of third molar development and its use as an estimator of chronological age. J Forensic Sci 38: $379-390$

14. Haavikko K (1970) The formation and the alveolar and clinical eruption of the permanent teeth. An orthopantomographic study. Suom Hammaslaak Toim 66 103-170.

15. Harris MJ, Nortjé CJ (1984) The mesial root of the third mandibular molar. A possible indicator of age. J Forensic Odontostomatol 2: 39-43.

16. Kullman L, Johanson $G$, Akesson $L$ (1992) Root development of the lower third molar and its relation to chronological age. Swed Dent J 16: 161-167.

17. Schmeling A, Grundmann C, Fuhrmann A, Kaatsch HJ, Knell B, et al. (2008) Criteria for age estimation in living individuals. Int J Legal Med 122: 457-460

18. Dhanjal KS, Bhardwaj MK, Liversidge HM (2006) Reproducibility of radiographic stage assessment of third molars. Forensic Sci Int 159: S74-S77

19. Schmeling A, Kaatsch HJ, Marré B, Reisinger W, Riepert T, et al. Guidelines for age estimation in living individuals in criminal proceedings. Study Group of Forensic Age Estimation of the German Association for Forensic Medicine.

20. Olze A, Solheim T, Schulz R, Kupfer M, Schmeling A (2010) Evaluation of the radiographic visibility of the root pulp in the lower third molars for the purpose of forensic age estimation in living individuals. Int J Legal Med 124: 183-186.

21. Kellinghaus M, Schulz R, Vieth V, Schmidt S, Schmeling A (2010) Forensic age estimation in living subjects based on the ossification status of the medial clavicular epiphysis as revealed by thin-slice multidetector computed tomography. Int J Legal Med 124: 149-154.

22. Kreitner KF, Schweden FJ, Riepert T, Nafe B, Thelen M (1998) Bone age determination based on the study of the medial extremity of the clavicle. Eur Radiol 8: 1116-1122.

23. Kullman L (1995) Accuracy of two dental and one skeletal age estimation method in Swedish adolescents. Forensic Sci Int 75: 225-236.

24. Martin-de las Heras S, García-Fortea P, Ortega A, Zodocovich S, Valenzuela A (2008) Third molar development according to chronological age in populations from Spanish and Magrebian origin. Forensic Sci Int 174: 47-53.

25. Cameriere R, Brkic H, Ermenc B, Ferrante L, Ovsenik M, et al.(2008) The measurement of open apices of teeth to test chronological age of over 14-year olds in living subjects. Forensic Sci Int 174: 217-221.

26. Friedrich RE, Ulbricht C, Ljuba A Baronesse von Maydell (2003) The influence of wisdom tooth impaction on root formation. Ann Anat 185: 481-492.

27. Kasper KA, Austin D, Kvanli AH, Rios TR, Senn DR (2009) Reliability of third molar development for age estimation in a texas hispanic population: a comparison study. J Forensic Sci 54: 651-657.

28. De Salvia A, Calzetta C, Orrico M, De Leo D (2004) Third mandibular mola radiological development as an indicator of chronological age in a European population. Forensic Sci Int 146: S9-S12.

29. Meinl A, Tangl S, Huber C, Maurer B, Watzek G (2007) The chronology of third molar mineralization in the Austrian population - a contribution to forensic age estimation. Forensic Sci Int 169: 161-167.

30. Schmeling A, Reisinger W, Loreck D, Vendura K, Markus W (2000) Effects of ethnicity on skeletal maturation: consequences for forensic age estimations. In J Legal Med 113: 253-258.

31. Olze A, Bilang D, Schmidt S, Wernecke KD, Geserick G (2005) Validation of common classification systems for assessing the mineralization of third molars. Int J Legal Med 119: 22-26.

32. Knell B, Ruhstaller P, Prieels F, Schmeling A (2009) Dental age diagnostics by means of radiographical evaluation of the growth stages of lower wisdom teeth Int J Legal Med 123: 465-469.

33. Zeng DL, Wu ZL, Cui MY (2010) Chronological age estimation of third mola mineralization of Han in southern China. Int J Legal Med 124: 119-123.

34. Demirjian A, Goldstein H, Tanner JM (1973) A new system of dental age assessment. Hum Biol 45: 211-227.

35. Soomer H, Ranta H, Lincoln MJ, Penttilä A, Leibur E (2003) Reliability and validity of eight dental age estimation methods for adults. J Forensic Sci 48 : 149-152.

36. Griffin RC, Moody H, Penkman KE, Collins MJ (2008) The application of amino acid racemization in the acid soluble fraction of enamel to the estimation of the age of human teeth. Forensic Sci Int 175: 11-16 